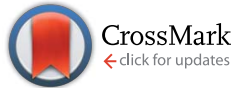

Cite this: RSC Adv., 2016, 6, 23288

Received 5th January 2016

Accepted 24th February 2016

DOI: $10.1039 / c 6 r a 00296 j$

www.rsc.org/advances

\title{
Fabrication of a multifunctional graphene/ polyvinylphosphonic acid/cotton nanocomposite via facile spray layer-by-layer assembly
}

\author{
Zoha Nooralian, Mazeyar Parvinzadeh Gashti* and Izadyar Ebrahimi
}

\begin{abstract}
Graphene is a well-known emerging material with a wide range of applications. Despite its recent uses in polymer science, the immobilization of graphene on textile substrates is a major research thrust. Layerby-layer (LBL) coating is a simple and cost-effective approach for stabilizing nanoparticles on different substrates to control properties, depending on the number of deposited layers. We assembled cationic graphene sheets using polyvinylphosphonic acid as an anionic thermal-resistant polymer on cotton via LBL coating. Fourier transform infrared spectra of the produced nanocomposite confirmed interfacial interactions among the graphene sheets, the polyvinylphosphonic acid and cotton in the coating layers; $\mathrm{X}$-ray diffraction spectra revealed no changes in the cellulose bulk structure due to these interactions. Contact-angle measurements and thermogravimetric analyses showed that graphene and polyvinylphosphonic acid improved the thermal stability and hydrophobicity of cotton. Our results also suggest that graphene and polyvinylphosphonic are not only able to protect cotton against solar ultraviolet rays but also possess excellent near infrared reflectivity, electrical conductivity and electromagnetic shielding. These beneficial properties make nanocomposites promising structures for multifunctional applications.
\end{abstract}

\section{Introduction}

Graphene is a two-dimensional planar carbon lattice with multifunctional applications in sensors, wires, microactuators, coatings, solid electrolytic capacitors, displays, polymeric batteries, electronic devices and filtration membranes. ${ }^{\mathbf{1 , 2}}$ Significant efforts in recent years have focused on coating different substrates with graphene via chemical vapor deposition, dip coating, spin coating, spray coating and the electrophoretic deposition method. ${ }^{3}$ The primary goal of such coating is to improve the performance of polymers and metals thanks to the intrinsic excellent optical, mechanical, thermal and electrical properties of graphene. ${ }^{4}$

Another field of interest to coating experts is the use of graphene on textiles through dyeing and dip-pad-dry methods. Two research groups have recently used the conventional dyeing method to immobilize graphene on acrylic and polyester to produce electrically conductive textiles. ${ }^{\mathbf{5 , 6}}$ Shateri-Khalilabad and Yazdanshenas have studied the influence of reducing agents $\left(\mathrm{NaBH}_{4}, \mathrm{~N}_{2} \mathrm{H}_{4}, \mathrm{C}_{6} \mathrm{H}_{8} \mathrm{O}_{6}, \mathrm{Na}_{2} \mathrm{~S}_{2} \mathrm{O}_{4}\right.$ and $\left.\mathrm{NaOH}\right)$ and reduction time on graphene coatings on cotton. These authors obtained the best conductivity and mechanical performance of the coating using $\mathrm{Na}_{2} \mathrm{~S}_{2} \mathrm{O}_{4} \cdot{ }^{7,8}$ This group has continued their

coating research on cotton with graphene/ $\mathrm{TiO}_{2}$ nanocomposites. They recently coated cotton with graphene oxide (GO) using a simple dip-coating method. Next, they immersed the samples in $\mathrm{TiCl}_{3}$ aqueous solution to produce graphene/ titanium dioxide nanocomposites. According to these results, multifunctional cotton is achievable with electro-conductive, self-cleaning, antibacterial, antifungal and non-toxic properties. ${ }^{9,10}$ Similar photocatalytic polyester fabrics based on GO/ $\mathrm{TiO}_{2}$ nanocomposites have been recently produced by Molina et al. ${ }^{11-13}$ Additional studies by Ramasundaram et al., ${ }^{14} \mathrm{Qu}$ et al. ${ }^{15}$ and Tang et al. ${ }^{16}$ have focused on producing hydrophobic poly(propylene), ultraviolet (UV)-blocking cotton and electroconductive cellulosic paper, respectively, using the dip-coating method. Moreover, a research group produced electroconductive fabrics using polyurethane (PU) for stabilizing GO as a sheet dyestuff. ${ }^{17}$ A graphitic thin layer was recently introduced by Javed et al. onto wool and cotton fibers under UV energy. UV radiation has been shown to be an efficient and costeffective way to reduce GO to graphene. ${ }^{18}$ More recently, graphene-coated cotton and polyester/cotton fabrics have been produced for dye-sensitized solar cells and conductors via the chemical reduction of GO. ${ }^{19-21}$ Plasma treatment is known to be an environmentally physical method to improve the adhesion of different compounds on textile fibers. ${ }^{22-26}$ In this regard, Molina et al. used atmospheric pressure with the dielectric barrier discharge modality to increase the surface adhesion of reduced GO (RGO) on polyester. These authors applied a layer of protein 
bovine serum albumin as an intermediate layer for selfassembly of GO on plasma-treated fabrics. They also showed that the conductivity of polyester coated with polypyrrole/GO nanocomposite was highly dependent on the GO content. ${ }^{27}$

Despite the previous methods used for embedding graphene on textile substrates, the development of new techniques for producing graphene functionalized textiles is still a challenge. This problem owes to the fact that there is no attractive force between carbon-based materials and textiles. In this regard, previous research studies have largely focused on textile coating with graphene via conventional "dip and dry" method, and only two research programs have described the LBL coating of graphene on cotton. In this regard, the research of Huang et al. is worthy of note. ${ }^{28}$ These authors suggested that nanocoatings assembled with acrylamide polymer and graphene enhanced the thermal stability and flame retardancy of cotton fabric. In another study, cotton fabrics showed extraordinary electrical and robust ultraviolet protective properties by coating graphene doped poly(3,4-ethylenedioxythiophene):poly(styrenesulfonate) (PEDOT:PSS) and chitosan. ${ }^{29}$

The present study introduces a facile method for embedding graphene on cotton surfaces via the LBL method. For this purpose, we employed vinylphosphonic acid as a polymerizable monomer due to the fact that it has been shown to be an effective compound for functionalizing textile substrates; it also possesses several advantages. We used different analytical tools to evaluate the physical and chemical properties of the coated cotton samples.

\section{Experimental}

\subsection{Materials}

We used a mercerized plain knitted $100 \%$ cotton fabric supplied by Yazdbaf Fabrics Company (Yazd, Iran). $\mathrm{COOH}$ functionalized graphene powder (FGN) (thickness: $2-18 \mathrm{~nm}$ ) with a purity of 99.5\% was purchased from Nanosany Corporation (Iran). Its volume resistivity was $4 \times 10^{-4} \mathrm{ohm} \mathrm{cm}$, and its average diameter was approximately 4-12 $\mu \mathrm{m}$. Vinylphosphonic acid was supplied by Archimica (Germany), and this acid had a density of $1.37 \mathrm{~g} \mathrm{~cm}^{-3}$ and a purity of 98\%. Azo-bisisobutyronitrile and $N, N, N$-cetyltrimethylammonium bromide (CTAB) were provided by Merck Chemical Co. (Germany).

\subsection{Preparation of spray containing colloids and the cotton coating}

We prepared two colloidal sprays for the LBL coating of cotton according to our previously published studies. ${ }^{30-32}$ For the first spray, different colloidal dispersions were developed using 10 and $20 \mathrm{mg} \mathrm{ml}^{-1}$ FGN separately mixed with $5 \mathrm{mg} \mathrm{ml}^{-1}$ CTAB in deionized water. The colloidal dispersions were then treated with ultrasonic waves at $30{ }^{\circ} \mathrm{C}$ for $4 \mathrm{~h}$ to produce stable colloids. For the second spray, we mixed $3 \% \mathrm{w} / \mathrm{w}$ vinylphosphonic acid with $0.3 \% \mathrm{w} / \mathrm{w}$ azo-bis-isobutyronitrile in deionized water under stirring conditions at $30{ }^{\circ} \mathrm{C}$ for $4 \mathrm{~h}$.

We conducted LBL coating of cotton using alternate spraying with the following colloids for $10 \mathrm{~s}$ : (a) the colloidal dispersion of FGN; (b) immersion in deionized water; (c) a mixture of vinylphosphonic acid and azo-bis-isobutyronitrile; and (d) immersion in deionized water. The spraying cycle was repeated until we recovered a 10-layer graphene/polyvinylphosphonic acid coating on the cotton. The coated cotton fabrics were then dried at $60{ }^{\circ} \mathrm{C}$ and cured at $100{ }^{\circ} \mathrm{C}$ for $60 \mathrm{~min}$.

\subsection{Characterization techniques}

Zeta potential measurements of the colloidal dispersions of FGN was performed using a nano-scale potential analyzer (Malvern Zetasizer 3000HS, Malvern Instruments Ltd, United Kingdom).

We evaluated the chemical properties of the coated fabrics using a Fourier transform infrared (FTIR) spectroscope (Bruker, United Kingdom) over the range $450-4000 \mathrm{~cm}^{-1}$.

We evaluated the physical structure of the samples using wide-angle X-ray diffractometry (XRD) with a computerized XRD instrument (XPERT-MPD, Philips, United Kingdom). We conducted the measurements using Ni-filtered $\mathrm{Cu} \mathrm{Ka}$ radiation generated at $40 \mathrm{kV}(k 1 / 40.1542 \mathrm{~nm})$ and $30 \mathrm{~mA}$. According to our earlier study, we used the following equation for the crystallinity percentage of the coated fabrics:

$$
C_{x} \%=\frac{I_{\mathrm{c}}}{I_{\mathrm{c}}+I_{\mathrm{a}}} \times 100
$$

where $C_{x} \%$ is the crystallinity percentage of cotton, $I_{\mathrm{c}}$ is the intensity of the XRD of the crystalline area, and $I_{\mathrm{a}}$ is the intensity of the XRD of the amorphous region.

We assessed the surface of the coated cotton using a scanning electron microscope (SEM) XL30, Philips. We coated the cotton textiles with a thin layer of gold $(10 \mathrm{~nm})$ using a sputter coater (SCDOOS-Baltec, Switzerland).

We evaluated the wettability of the textiles by measuring the water contact angle on their surfaces using a Kruss G10 instrument (Germany). We carried out our measurements at room temperature and $65 \%$ relative humidity.

We examined the thermal degradation properties of the coated fabrics using a TGA-PL thermoanalyzer (United Kingdom). For this purpose, $5 \mathrm{mg}$ of each sample was exposed to heat under $\mathrm{O}_{2}$ gas at a rate of $5{ }^{\circ} \mathrm{C} \mathrm{min}{ }^{-1}$ from room temperature to $500{ }^{\circ} \mathrm{C}$.

We determined the solar UV protection and near-infrared (NIR) absorption properties of samples at normal incidence over the spectral ranges 190-450 and 800-2300 $\mathrm{nm}$, respectively. This experiment was performed using a double-beam spectrophotometer (JASCO model V-570 UV-VIS-NIR, Japan).

We also measured the electrical resistance properties of the coated textiles at the surface according to the American Association of Textile Chemists and Colorists (AATCC) Test Method 76-2005 using a four-point probe technique (Sunwa YX360TRES, Japan). We evaluated the electrical resistance of each side of the fabrics five times, and we computed the average values. The experiment was carried out at a temperature and relative humidity of $24{ }^{\circ} \mathrm{C}$ and $65 \%$, respectively. The surface conductivity of the composite materials was calculated using the following equation: 


$$
\rho=\frac{R d w}{l}
$$

where $\rho$ is the surface resistivity (ohms per square), $R$ is resistance $(\mathrm{ohm}), d$ is the sample thickness $(\mathrm{cm}), l$ is the distance between the electrodes $(\mathrm{cm})$ and $w$ is the width of each electrode (cm).

$$
\sigma=\frac{1}{\rho}
$$

$\sigma$ is the conductivity $\left(\mathrm{S} \mathrm{cm}^{-1}\right)$ and $\rho$ is the surface resistivity (ohms per square).

We also evaluated the conductivity of coated cotton after washing procedure according to ISO 105-C03.

We used a network analyzer (HP 8410C) and reflection \& transmission test unit (HP 8743B) operating over the frequency range of $8.0-12.0 \mathrm{GHz}$ (X-band) to measure the electromagnetic shielding effectiveness (EMI) of the synthesized materials according to ASTM D4935-99.

\section{Results and discussion}

\subsection{Chemical structures and reaction mechanisms}

Fig. 1 schematically illustrates the process for dispersion of FGN using CTAB under ultrasonification. Producing a stable colloidal dispersion of carbon-based compounds for coating purposes is one of the primary challenges facing textile engineering scientists. ${ }^{33}$ In graphene, there are covalent bonds between the carbon atoms in each sheet; weak van der Waals forces exist between sheets. Graphene has an extremely hydrophobic nature and tends to aggregate in water in the absence of dispersing agents due to the lack of polar domains on its surface. ${ }^{34}$ One way to overcome this problem is to generate carboxylic, amine or alcoholic groups on the graphene surface via covalent attachment. It has been previously shown that the presence of these groups yields a drastic improvement in graphene hydrophilicity and reactivity with different substrates. ${ }^{35}$ Dispersion of graphene nanoplatelets can be facilitated via surfactants in a sonification process due to the combination of

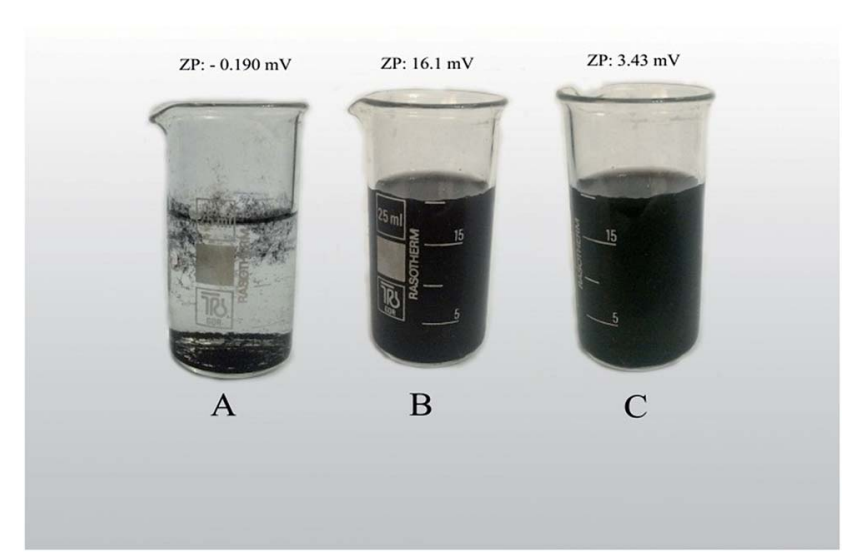

Fig. 1 Stability of different colloidal dispersions in water after 6 months: (a) pristine FGN, (b) $10 \mathrm{mg} \mathrm{ml}^{-1}$ FGN/CTAB colloidal dispersion, (c) $20 \mathrm{mg} \mathrm{ml}^{-1} \mathrm{FGN} / \mathrm{CTAB}$ colloidal dispersion. mechanical energy and the surface-adsorption phenomenon. ${ }^{36}$ We measured the zeta potential values for 10 and $20 \mathrm{mg} \mathrm{ml}^{-1}$ FGN in colloidal dispersions when CTAB was added and compared out findings with an FGN colloidal dispersion with no dispersing agent. The zeta potential of FGN was $-0.190 \mathrm{mV}$, and the zeta potential took on positive values of 16.1 and 3.43 $\mathrm{mV}$ for the 10 and $20 \mathrm{mg} \mathrm{ml}^{-1}$ FGN/CTAB colloidal dispersions, respectively. The monomers of CTAB cannot form micelles at a concentration range below the critical micelle concentration (CMC); higher concentrations lead to self-assembling of different surfactant structures. Despite the presence of carboxylic groups on the sheet surfaces, graphene showed poor dispersibility in water with a negative zeta potential value (Fig. 1a). The addition of CTAB at a higher concentration than the CMC in the FGN dispersion (as used in this study) following by ultrasonic vibration resulted in dispersions with positive zeta potential values that maintained their stability for 6 months (Fig. 1b and c). We obtained similar results in our previous studies for carbon nanotube dispersion in water with the aid of CTAB. ${ }^{31,37}$ Fig. 2 schematically shows the mechanism of FGN dispersion in the presence of CTAB. Since we obtained positive zeta potential values for the FGN/CTAB colloidal dispersions, two mechanisms can be proposed to explain of inhibition of FGN precipitation in water as confirmed elsewhere for gold nanoparticles. ${ }^{38,39}$ First, the cationic head domains of CTAB are attracted to the FGN carboxylate groups by Coulombic forces, thereby forming a multilayer of lamellar phases with hydrophobic interactions among the alkyl chain cores. Note that the cationic head domains will be assembled on the outer layer of $\mathrm{CTAB}$ lamellar structure, which results in an overall positive zeta potential.

Another possible mechanism to explain the stabilization of the FGN dispersion is the generation of spherical micelles by $\mathrm{CTAB}$ at a higher concentration than the CMC. In this regard, the cationic domains of $\mathrm{CTAB}$ are assembled on the exterior surface of the spheres, and the hydrophobic tails are formed on the interior side. Such self-associated structures are organized at the FGN surfaces and result in a stabilized colloidal dispersion. We also obtained higher zeta potential values for the 10

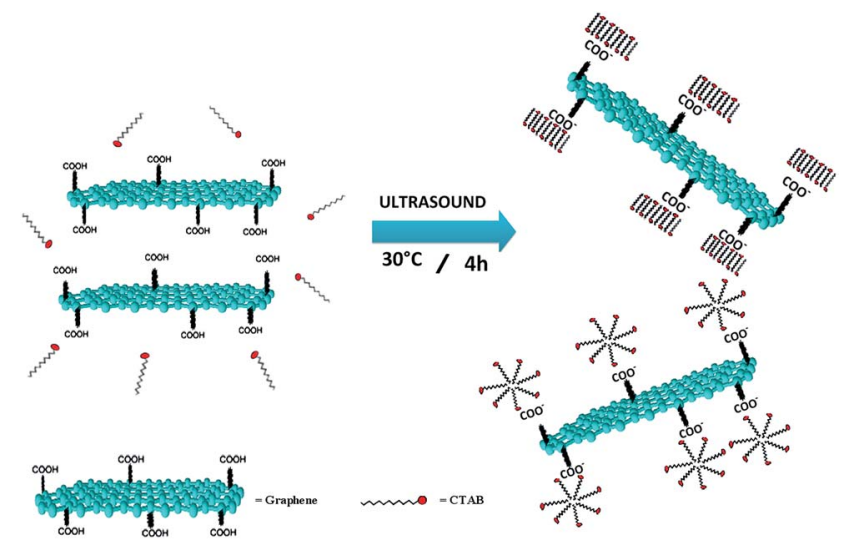

Fig. 2 The mechanism of the dispersion of FGN in water using CTAB and ultrasonic vibration. 
$\mathrm{mg} \mathrm{ml} \mathrm{m}^{-1}$ FGN/CTAB colloidal dispersion compared with the 20 $\mathrm{mg} \mathrm{ml}^{-1} \mathrm{FGN}$. This result can be explained by the availability of more CTAB molecules for a lower content of FGN dispersion to produce multilayered or spherical micelles.

Fig. 3 shows the steps for preparing graphene/ polyvinylphosphonic acid/cotton nanocomposites via spray LBL coating. The first step involves spraying the FGN/CTAB colloidal dispersion on the cotton surface. FGN can be simply attracted to the cotton surface by ionic interactions, van der Waals forces and hydrogen bondings forming the first layer..$^{40} \mathrm{In}$ the next step, vinylphosphonic acid and azo-bis-isobutyronitrile are sprayed on the cotton surface as a second layer to provide an anionic coating on top of the first layer. We repeated this procedure 10 times, and the resulting samples were finally cured in an oven to produce multilayered graphene/ polyvinylphosphonic acid/cotton nanocomposites.

In Fig. 4, we show the FTIR spectra of untreated cotton, FGN powder, and cotton coated with polyvinylphosphonic acid together with graphene/polyvinylphosphonic acid/cotton nanocomposites prepared with 10 coating cycles of FGN/CTAB colloidal dispersion and polyvinylphosphonic acid. The FTIR spectrum of cellulose is indicative of several $\mathrm{CH}$ stretching, scissoring, rocking and bending vibrations at frequency ranges of $2850-2950,1430-1470,1250-1420$ and $700-1050 \mathrm{~cm}^{-1}$, respectively. The intermolecular $\mathrm{O}-\mathrm{H}$ stretching of cellulose chains appears at $3429 \mathrm{~cm}^{-1}$. The bands at 1577 and $1706 \mathrm{~cm}^{-1}$ represent $\mathrm{C}=\mathrm{O}$ stretching vibrations, and the peaks appearing at $1095,1175,1206$ and $1238 \mathrm{~cm}^{-1}$ confirm C-O-C symmetric and asymmetric stretching vibrations (ether bonds). ${ }^{41}$ For FGN, the appearance of $\mathrm{O}-\mathrm{H}$ stretching is well represented as strong bands at 3436 and $1400 \mathrm{~cm}^{-1}$. The carboxylic acid groups on graphene appear at $1628 \mathrm{~cm}^{-1}$ as a $\mathrm{C}=\mathrm{O}$ stretching vibration. The band at $1458 \mathrm{~cm}^{-1}$ is due to the $\mathrm{C}-\mathrm{C}$ stretching of graphene sheets. Furthermore, the bands at 1026 and $1095 \mathrm{~cm}^{-1}$ are indicative of the C-O-C modes. ${ }^{42}$ We used FTIR spectroscopy to evaluate the chemical reactions between polyvinylphosphonic acid and cotton without FGN. According to Fig. 4c, the cotton characteristic peak at $2106 \mathrm{~cm}^{-1}$ was shifted to $2116 \mathrm{~cm}^{-1}$, which is due to the presence of the $\mathrm{CN}$ groups in azo-bis-

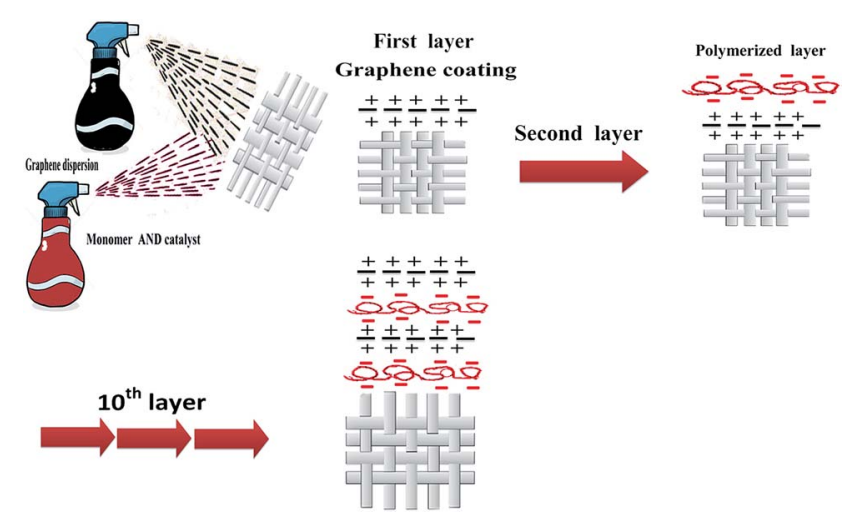

Fig. 3 Schematic diagram of the fabrication process of graphene/ polyvinylphosphonic acid/cotton nanocomposites via spray LBL assembly.

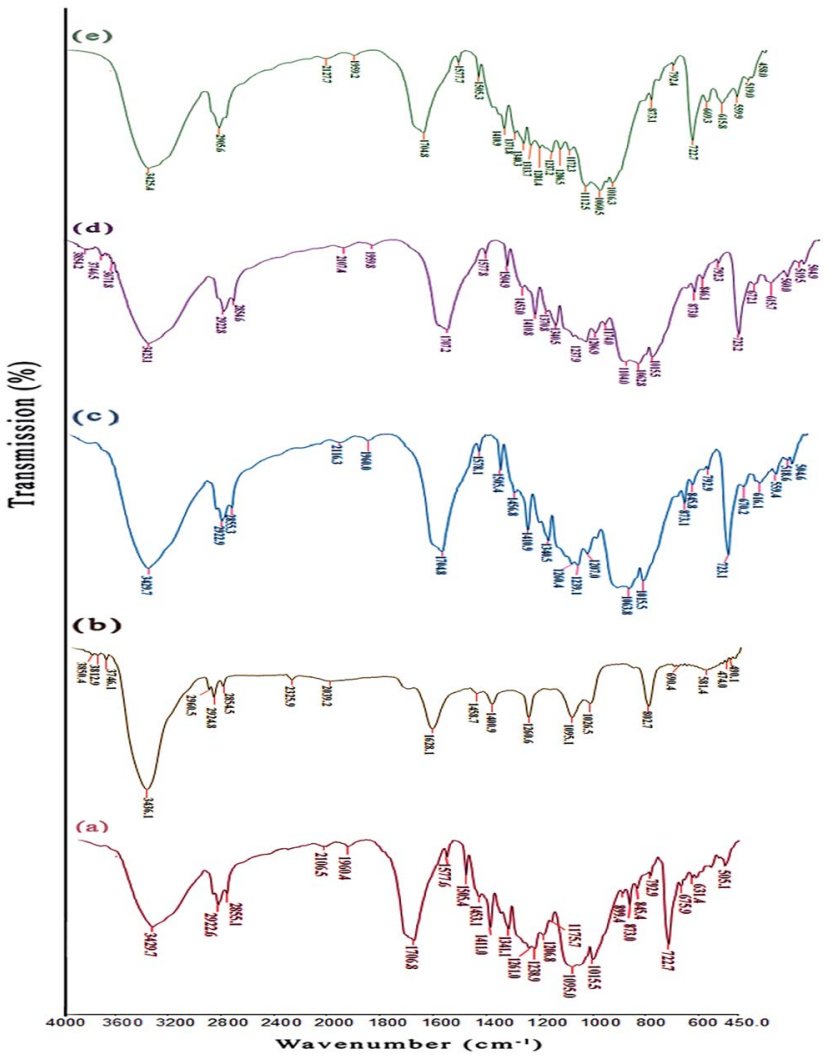

Fig. 4 FTIR spectra of different samples: (a) untreated cotton, (b) FGN powder, (c) cotton coated with polyvinylphosphonic acid, (d) graphene/polyvinylphosphonic acid/cotton nanocomposites prepared with 10 coating cycles of $10 \mathrm{mg} \mathrm{ml}^{-1}$ FGN/CTAB colloidal dispersion and polyvinylphosphonic acid, (e) graphene/polyvinylphosphonic acid/cotton nanocomposites prepared with 10 coating cycles of 20 $\mathrm{mg} \mathrm{ml}^{-1} \mathrm{FGN} / \mathrm{CTAB}$ colloidal dispersion and polyvinylphosphonic acid.

isobutyronitrile (initiator) after surface polymerization of the monomer. Furthermore, the intensity of a band at $1095 \mathrm{~cm}^{-1}$ decreased, and two bands appeared at 1063 and $559 \mathrm{~cm}^{-1}$. We attribute these changes to the $\mathrm{P}=\mathrm{O}$ and $\mathrm{P}-\mathrm{O}-\mathrm{C}$ stretching vibrations of polyvinylphosphonic acid, which are in good agreement with our previously reported study ${ }^{43}$ After 10 coating cycles of $10 \mathrm{mg} \mathrm{ml}^{-1}$ FGN/CTAB colloidal dispersion and polyvinylphosphonic acid on cotton (Fig. 4d), we observed several changes in the FTIR spectra; these changes included the appearance of new peaks at approximately 1062, 615 and 560 $\mathrm{cm}^{-1}$, the shifting of a band from 1095 to $1104 \mathrm{~cm}^{-1}$, the disappearance of a band at $1261 \mathrm{~cm}^{-1}$, and a decrease in the intensity of bands at 1707 and $1410 \mathrm{~cm}^{-1}$. For the cotton sample coated with a higher concentration of FGN $\left(20 \mathrm{mg} \mathrm{ml}^{-1} \mathrm{FGN} /\right.$ CTAB colloidal dispersion and polyvinylphosphonic acid), we observed more changes in the FTIR spectrum. These changes included a decrease in the intensity of the bands at 1706, 1411, $1261,1238,873,845$ and $722 \mathrm{~cm}^{-1}$, the appearance of two bands at 1060 and $559 \mathrm{~cm}^{-1}$ and the disappearance of a band at 505 $\mathrm{cm}^{-1}$. On this subject, we also observed an increase in the intensity of bands at 669 and $615 \mathrm{~cm}^{-1}$ and shifting of bands 
from 2922, 2106 and $1095 \mathrm{~cm}^{-1}$ to 2905,2127 and $1112 \mathrm{~cm}^{-1}$, respectively.

In terms of these characteristic peaks of the FGN/ polyvinylphosphonic coated cotton, several research groups have studied the interactions between cotton and graphene using FTIR spectroscopy. ${ }^{\mathbf{9 1 0 , 2 9}}$ Karimi et al. evaluated the FTIR spectra of graphene/ $\mathrm{TiO}_{2}$ nanocomposite-coated cellulose and found interfacial interactions between the graphene and the $\mathrm{TiO}_{2}$. According to their study, Ti-O-Ti and Ti-O-C bonds formed between the inorganic nanocomposite and cotton and resulted in the presence of new absorption peaks at a lower frequency range (roughly $1000 \mathrm{~cm}^{-1}$ ). ${ }^{9,10}$ This group utilized methyltrichlorosilane (MTCS) in another study to embed graphene on the cotton surface. They found, interestingly, the presence of stretching vibrations of $\mathrm{Si}-\mathrm{C}$ bands due to reactions among MTCS, graphene and cotton. ${ }^{8}$ Similarly, Xu et al. observed the appearance of a new peak at $1568 \mathrm{~cm}^{-1}$ in $\mathrm{GO} /$ cotton composite fabrics; this peak was attributed to the $\mathrm{C}=\mathrm{C}$ skeletal vibration of graphene. ${ }^{19}$ Similarly, Sahito et al. produced graphene-coated cotton as counter electrode for dyesensitized solar cells and observed some similar changes as ours in the FTIR spectra of cotton; these authors noted the appearance of new peak at $875 \mathrm{~cm}^{-1} .^{20}$ It is worth mentioning a comparative study conducted by Huang et al. in 2012. These authors fabricated polyacrylamide and exfoliated GO via a LBL coating to consider all of the possible interactions among the nanocomposite layers and cellulose. ${ }^{28}$ Here, we found that the changes observed in our FTIR spectra ensured a successful coating of graphene/polyvinylphosphonic acid nanocomposite on the cotton surface.

\subsection{Evaluation of crystallinity}

XRD spectroscopy is an important analytical tool for studying the influence of coatings on the physical properties and crystallinity changes of polymers and textiles. ${ }^{44}$ XRD diffraction patterns, together with the calculated parameters for the untreated cotton, cotton coated with polyvinyl phosphonic acid and graphene/polyvinylphosphonic acid/cotton nanocomposites, are shown in Fig. 5 and Table 1. Cellulose generally possesses three characteristic reflections at $2 \theta=17.9^{\circ}, 23.2^{\circ}$ and $26.5^{\circ}$ relating to the $d(110), d(200)$ and $d(002)$ Bragg reflections. According to XRD patterns, the position of the reflection peaks did not considerably change for cellulose after LBL deposition of FGN and polyvinylphosphonic acid. Similar results have been reported elsewhere for graphene coatings over cotton, polyester and polypropylene fibers. ${ }^{12,17,45}$ Researchers have found that graphene peaks are not detectable on coated textiles if successful exfoliation and uniform assembly is achieved. On a similar note, we also calculated the crystallinity percent and crystal size of the cellulose after coatings according to eqn (1). Based on our results, the changes in crystallinity

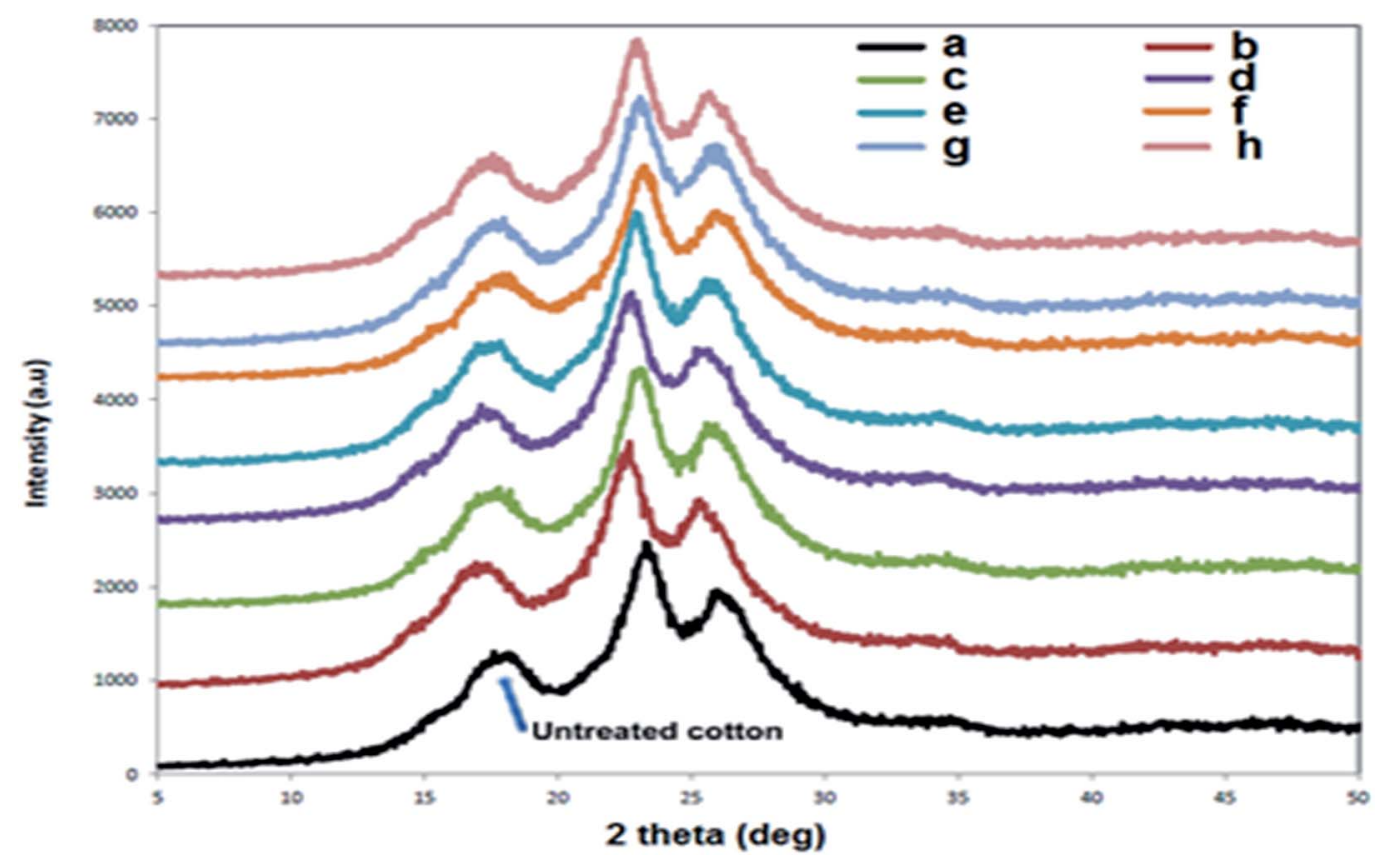

Fig. 5 XRD spectra of different samples: (a) untreated cotton, (b) cotton coated with polyvinylphosphonic acid, (c) graphene/polyvinylphosphonic acid/cotton nanocomposite prepared with 2 coating cycles of $10 \mathrm{mg} \mathrm{m}^{-1}$ FGN/CTAB colloidal dispersion and polyvinylphosphonic acid, (d) graphene/polyvinylphosphonic acid/cotton nanocomposite prepared with 5 coating cycles of 10 mg ml ${ }^{-1} \mathrm{FGN} / \mathrm{CTAB}$ colloidal dispersion and polyvinylphosphonic acid, (e) graphene/polyvinylphosphonic acid/cotton nanocomposite prepared with 10 coating cycles of $10 \mathrm{mg} \mathrm{ml}^{-1}$ FGN/CTAB colloidal dispersion and polyvinyl phosphonic acid, (f) graphene/polyvinylphosphonic acid/cotton nanocomposite prepared with 2 coating cycles of $20 \mathrm{mg} \mathrm{ml}^{-1}$ FGN/CTAB colloidal dispersion and polyvinylphosphonic acid, (g) graphene/polyvinylphosphonic acid/cotton nanocomposite prepared with 5 coating cycles of $20 \mathrm{mg} \mathrm{ml}^{-1}$ FGN/CTAB colloidal dispersion and

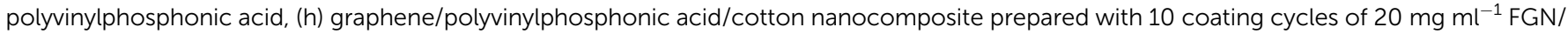
CTAB colloidal dispersion and polyvinylphosphonic acid. 
Table 1 XRD-calculated parameter of different samples produced in this study

\begin{tabular}{|c|c|c|c|c|c|c|c|c|c|c|}
\hline \multirow[b]{2}{*}{ Sample code } & \multirow[b]{2}{*}{$\begin{array}{l}\text { Number of } \\
\text { coating cycles }\end{array}$} & \multirow{2}{*}{$\begin{array}{l}\text { Graphene } \\
\text { content } \\
\text { in dispersion } \\
\left(\mathrm{mg} \mathrm{ml} \mathrm{ml}^{-1}\right)\end{array}$} & \multirow[b]{2}{*}{$\begin{array}{l}\text { Crystallinity } \\
\text { index }(\%)\end{array}$} & \multirow[b]{2}{*}{$\begin{array}{l}\text { Crystallite } \\
\text { dimension } \\
(\mathrm{nm})(200)\end{array}$} & \multicolumn{2}{|l|}{$(110)$} & \multicolumn{2}{|l|}{$(200)$} & \multicolumn{2}{|l|}{$(002)$} \\
\hline & & & & & $\begin{array}{l}2 \theta \\
(\mathrm{deg})\end{array}$ & $\begin{array}{l}d \text {-spacing } \\
(\mathrm{nm})\end{array}$ & $\begin{array}{l}2 \theta \\
\text { (deg) }\end{array}$ & $\begin{array}{l}d \text {-spacing } \\
(\mathrm{nm})\end{array}$ & $\begin{array}{l}2 \theta \\
(\mathrm{deg})\end{array}$ & $\begin{array}{l}d \text {-spacing } \\
(\mathrm{nm})\end{array}$ \\
\hline Untreated cotton & - & - & 69.84 & 5.07 & 17.92 & 0.494 & 23.25 & 0.382 & 25.96 & 0.343 \\
\hline $\begin{array}{l}\text { Cotton coated with } \\
\text { polyvinylphosphonic acid }\end{array}$ & 10 & - & 69.06 & 4.77 & 16.92 & 0.523 & 22.63 & 0.393 & 25.32 & 0.351 \\
\hline Graphene/polyvinyl- & 2 & 10 & 70.37 & 5.40 & 17.8 & 0.498 & 22.82 & 0.389 & 25.56 & 0.348 \\
\hline phosphonic acid/cotton & 5 & 10 & 70.76 & 5.79 & 17.4 & 0.509 & 22.76 & 0.390 & 25.16 & 0.354 \\
\hline nanocomposite & 10 & 10 & 72.73 & 6.01 & 17.48 & 0.507 & 22.92 & 0.388 & 25.76 & 0.345 \\
\hline & 2 & 20 & 71.13 & 5.41 & 17.96 & 0.493 & 23.20 & 0.383 & 26 & 0.342 \\
\hline & 5 & 20 & 69.29 & 4.50 & 17.6 & 0.503 & 23.08 & 0.385 & 25.92 & 0.343 \\
\hline & 10 & 20 & 69.40 & 4.76 & 17.56 & 0.0504 & 23 & 0.376 & 25.68 & 0.346 \\
\hline
\end{tabular}

percent and crystal size were negligible for cellulose coated with 5 and 10 cycles of FGN/CTAB colloidal dispersion and polyvinylphosphonic acid. These results are consistent with the FTIR spectra of the samples that confirm the surface adsorption of FGN. We recently investigated the effects of cellulose surface oxidation on the performance of the fluorocarbon coating, and we found no changes in the cellulose crystalline structure.

\subsection{Surface morphological studies}

It is well-known that SEM is an important analytical method for the surface identification of nanoparticle-coated polymers. ${ }^{46}$ The SEM data of the untreated cotton, graphene/ polyvinylphosphonic acid/cotton nanocomposites prepared via 5- and 10-coating cycles and the cotton fiber cross-linked with polyvinylphosphonic acid are illustrated in Fig. 6a-e. The untreated cotton fibers generally exhibited groove-dominated

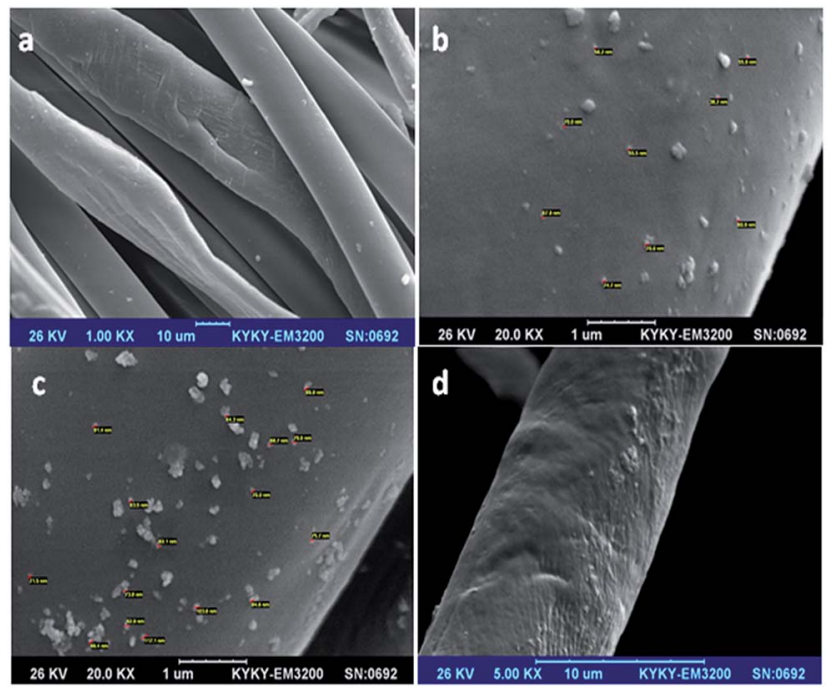

Fig. 6 SEM micrographs of: (a) untreated cotton, (b) cotton coated with 10 cycles of $10 \mathrm{mg} \mathrm{ml}^{-1}$ FGN/CTAB colloidal dispersion and polyvinylphosphonic acid, (c) cotton coated with 10 cycles of $20 \mathrm{mg}$ $\mathrm{ml}^{-1}$ FGN/CTAB colloidal dispersion and polyvinylphosphonic acid, (d) cotton coated with polyvinylphosphonic acid. surfaces with visible fibrils. Since there was no deposition of graphene on cotton, untreated fibers possess a relatively clean surface. However, the SEM image of cotton coated with 5 cycles of graphene/polyvinylphosphonic acid nanocomposite reveals a few aggregates of graphene on the fiber surface; these aggregates are smaller than $100 \mathrm{~nm}$ in size. It is important that the surface of the cotton sample coated with 10 cycles of graphene/ polyvinylphosphonic acid nanocomposites exhibited more aggregated nanoparticles. As shown in Fig. 6d, we did not use graphene for the sample; therefore, the polyvinylphosphonic acid produced a thin layer of coating on the cotton without any aggregation of nanoparticles. Several research groups immobilized GO on cotton and considered the microscopic images for characterization. ${ }^{7-\mathbf{1 0 , 1 5 - 1 7}}$ Huang et al. showed that GO does not cover the holes and woven structure of cotton. As a result, these authors showed that GO does not impede either the breathing or comfort properties of the cotton. ${ }^{28}$

\subsection{Water contact angle measurements}

In this study, we used an FGN/CTAB colloidal dispersion as a cationic functional composition to coat cotton; we also used vinylphosphonic acid as an anionic monomer to fix graphene on cotton. As several inorganic/organic hybrid layers are deposited on the cotton, changes in the contact angle values can be expected. Lavinia and Gheorghe have systematically reviewed the use of polyvinylphosphonic acid in different industries. ${ }^{47}$ These authors stated that this polymer has a wide range of applications such as acting as a drug-delivery hydrogel and a dental cement. In addition, our group recently used polyvinylphosphonic acid monomers to stabilize carbon nanotubes on cotton. We demonstrated that this hybrid coating acts as a flame retardant for cellulose. ${ }^{43}$ Considering the fact that cellulose is a hydrophilic polymer, it is extremely important to use water repellent coatings to achieve hydrophobic characteristics. It has been demonstrated that RGO coatings are able to increase the water contact angle on textiles due to their intrinsic hydrophobic characteristics. ${ }^{\mathbf{8 1 4}}$ We note that the number of graphene layers controls the value of the water contact angle; a larger number of coatings is associated with a stronger likelihood of achieving a higher water contact value. According to 
Fig. 7, the untreated cotton absorbed the water quickly; the water contact angle was $119^{\circ}$ for the cotton fabric coated with 1 cycle $10 \mathrm{mg} \mathrm{ml}^{-1}$ FGN/CTAB colloidal dispersion and polyvinylphosphonic acid. An increase in the number of coating cycles resulted in an increase in the water contact angles from $125^{\circ}$ to $133^{\circ}$. We should also note that the degree of cotton hydrophobicity intensified with an increase in the FGN content in the colloidal dispersion from 10 to $20 \mathrm{mg} \mathrm{ml}^{-1}$. ShateriKhalilabad and Yazdanshenas recently prepared superhydrophobic cotton using polymethylsiloxane and graphene. These authors demonstrated that graphene had a synergic effect on the water contact angle of polymethylsiloxane-coated cellulose. $^{8}$

\subsection{Evaluation of thermal properties}

Fig. 8 shows the thermal degradation of untreated cotton, cotton coated with polyvinylphosphonic acid and graphene/ polyvinylphosphonic acid/cotton nanocomposites prepared with 5,8 and 10 coating cycles. It goes without saying that the thermal degradation of textiles generally occurs in three areas: initial, main and char. ${ }^{48-50}$ In the first area, the cotton amorphous regions are damaged, and the surface-adsorbed water molecules are evaporated, which results in a weight loss of the material of approximately 5\%. Significant degradation of cellulose occurs from $300-450{ }^{\circ} \mathrm{C}$ due to the combustion of glucose and the degradation of the crystalline regions in the cellulose backbone. ${ }^{51}$ Because of the release of carbon dioxide in the third area of the thermal degradation curve, complete dehydration occurs and char is generated. We observed a higher thermal stability of the graphene/polyvinylphosphonic acid/ cotton nanocomposite prepared with 5 coating cycles due to the shift of the second area to higher temperatures between 250 and $450{ }^{\circ} \mathrm{C}$. Furthermore, the thermal stability of the nanocomposites was additionally improved by increasing the number of coating cycles to 8 or 10 . Similarly, we observed that

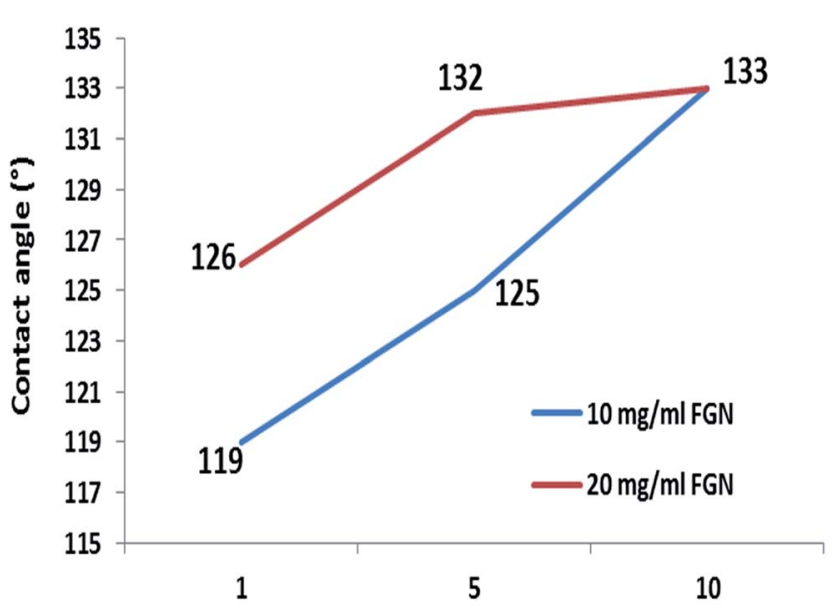

\section{Number of coating cycles}

Fig. 7 Changes in water contact angle of the graphene/polyvinylphosphonic acid/cotton nanocomposites prepared using two different graphene contents for 1,5 and 10 coating cycles.

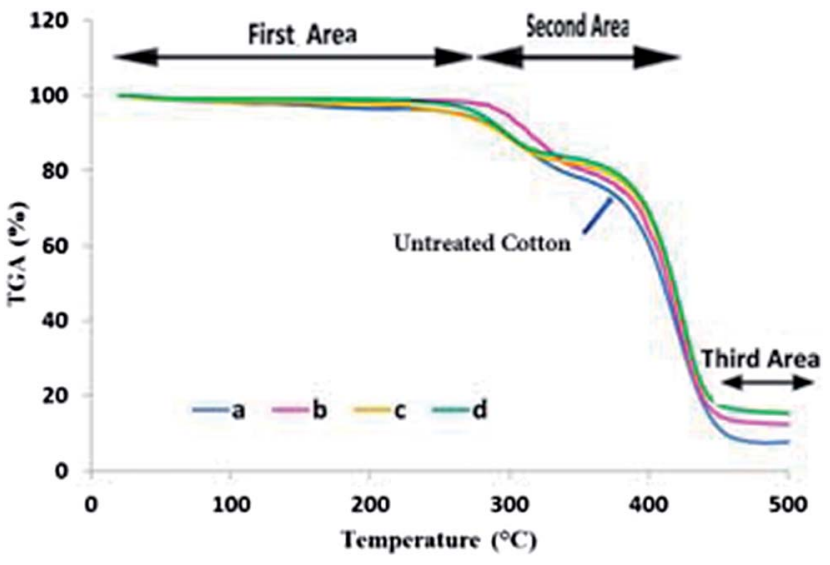

Fig. 8 The thermo-gravimetric analysis of different samples: (a) untreated cotton, (b) cotton coated with polyvinyl phosphonic acid, (c) graphene/polyvinylphosphonic acid/cotton nanocomposite prepared with 10 coating cycles of $10 \mathrm{mg} \mathrm{ml}^{-1}$ FGN/CTAB colloidal dispersion and polyvinyl phosphonic acid, (d) graphene/polyvinylphosphonic acid/cotton nanocomposite prepared with 10 coating cycles of $20 \mathrm{mg}$ $\mathrm{ml}^{-1} \mathrm{FGN} / \mathrm{CTAB}$ colloidal dispersion and polyvinylphosphonic acid.

the char content was higher for the graphene/ polyvinylphosphonic acid/cotton nanocomposites compared with the untreated cotton. We previously introduced several inorganic/organic hybrid nanocomposites on textiles that acted as synergistic thermal barriers. ${ }^{30-32,43,52,53}$ According to our findings, carboxylic acid containing crosslinkers, polyvinylphosphonic acid and polypyrrole were able to embed silicone oxide, silica/kaolinite, carbon nanotubes, zirconium oxide and silver on natural fibers. These cross-linkers improved the thermal stability of textiles due to their high heat resistance, heat insulation effect and the mass transport barrier of the nanoparticles. Two research groups have studied the thermal degradation of cotton after it is coated with graphene. ${ }^{28,40}$ Zhao et al. exposed GO-coated cotton to direct adsorption, radiationinduced cross-linking and chemical cross-linking. Although these authors introduced simple methods for immobilizing GO on cotton, their samples exhibited an inferior thermal stability compared with untreated cotton. ${ }^{40}$ Our results of the thermal stability of cotton are consistent with the findings of Huang et al. ${ }^{28}$ These authors added flame-retardant polyacrylamide/GO nanocomposites to cotton via LBL deposition and recovered a higher thermal stability compared with that of cotton.

\subsection{Assessment of solar UV protection and NIR reflection}

In Fig. 9, we show the UV reflection and NIR reflection spectra of untreated cotton, cotton coated with polyvinylphosphonic acid and graphene/polyvinylphosphonic acid/cotton nanocomposites prepared with 1,5 and 10 coating cycles of different colloidal dispersions of FGN/CTAB. The untreated cotton exhibited a high UV reflectance over the regime 190-290 nm. After coating the cotton with polyvinylphosphonic, we recovered UV absorption over this same regime. We note that the use of graphene in the cotton coatings increased the resistance of the cotton to UV damage. In this regard, the percent decrease in UV 

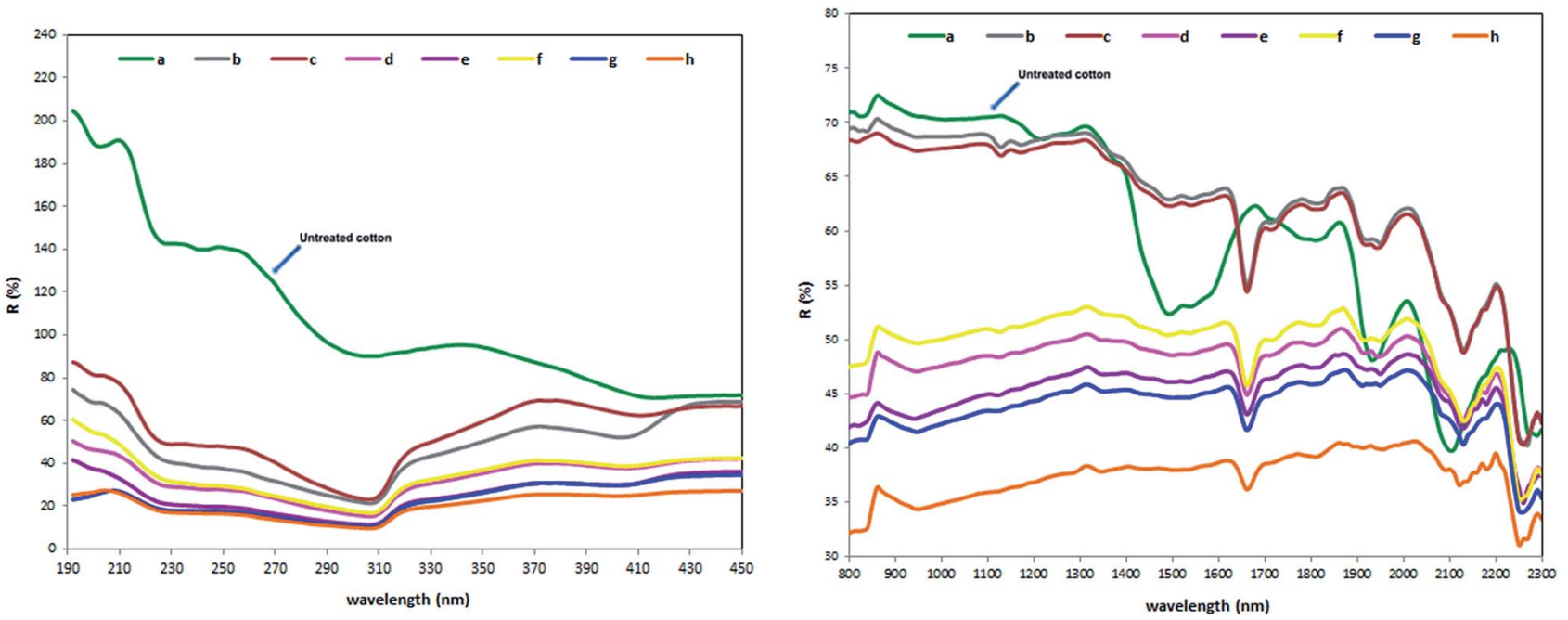

Fig. 9 UV reflectance (\%) (left) and NIR reflectance (\%) (right) of different samples: (a) untreated cotton, (b) cotton coated with polyvinylphosphonic acid, (c) graphene/polyvinylphosphonic acid/cotton nanocomposite prepared with 2 coating cycles of $10 \mathrm{mg} \mathrm{ml}^{-1} \mathrm{FGN} / \mathrm{CTAB}$ colloidal dispersion and polyvinylphosphonic acid, (d) graphene/polyvinylphosphonic acid/cotton nanocomposite prepared with 5 coating cycles of $10 \mathrm{mg} \mathrm{ml}^{-1}$ FGN/CTAB colloidal dispersion and polyvinylphosphonic acid, (e) graphene/polyvinylphosphonic acid/cotton nanocomposite prepared with 10 coating cycles of $10 \mathrm{mg} \mathrm{ml}^{-1} \mathrm{FGN} / \mathrm{CTAB}$ colloidal dispersion and polyvinylphosphonic acid, (f) graphene/polyvinylphosphonic acid/cotton nanocomposite prepared with 2 coating cycles of $20 \mathrm{mg} \mathrm{ml}^{-1}$ FGN/CTAB colloidal dispersion and

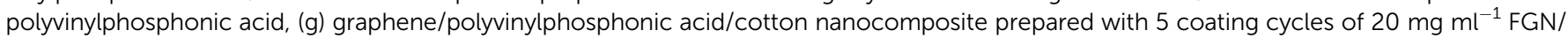
CTAB colloidal dispersion and polyvinylphosphonic acid, (h) graphene/polyvinylphosphonic acid/cotton nanocomposite prepared with 10 coating cycles of $20 \mathrm{mg} \mathrm{ml}^{-1} \mathrm{FGN} / \mathrm{CTAB}$ colloidal dispersion and polyvinylphosphonic acid.

reflectance depended on the number of coating layers and the graphene content. The UV reflectance of the cotton decreased in value after 1 coating cycle of graphene/polyvinylphosphonic acid nanocomposite, and it was additionally decreased when the number of coating cycles was increased from 5 to 10 . Moreover, the decrease in the UV reflection percentage of cotton was more pronounced over the spectral regime 190-450 nm when the content of graphene was increased from 10 to $20 \mathrm{mg}$ $\mathrm{ml}^{-1}$. Based on our results, polyvinylphosphonic acid had the smallest influence on the percent of UV light reflected; the graphene/polyvinylphosphonic acid/cotton nanocomposite prepared with 10 coating cycles of $20 \mathrm{mg} \mathrm{ml}^{-1}$ FGN/CTAB colloidal dispersion exhibited the most pronounced UV protection of all the samples.

To better protect textile substrates against solar rays, several research groups have proposed inorganic and organic materials as dyeing and coating reagents. ${ }^{54-56}$ Our results of UV reflection are consistent with the recent findings of Qu et al. ${ }^{15}$ and Tian et al. ${ }^{29}$ In brief, these authors introduced graphene as a novel UV blocking agent for cotton fabric. Qu et al. found, interestingly, that the unique two-dimensional planar structure of graphene played a key role in the absorption of UV rays. More recently, Karimi et al. ${ }^{10}$ and Molina et al. ${ }^{13}$ produced functional textile fabrics using $\mathrm{GO} / \mathrm{TiO}_{2}$ nanocomposite coating. According to their results, $\mathrm{GO}$ decreases the UV reflection of $\mathrm{TiO}_{2}$ due to its intrinsic absorption characteristics. $\mathrm{GO}$ can also promote the photocatalytic activity of $\mathrm{TiO}_{2}$ to oxidize organic materials due to its ability to transfer excited electrons. These results are additionally supported by the finds of $\mathrm{Hu}$ et al. in terms of graphene/PU-coated cotton fabrics. ${ }^{17}$
We have accordingly evaluated the NIR reflection properties of graphene on cotton, which has not been reported elsewhere on textiles. One can clearly observe that the NIR absorption values of the cotton sample coated with polyvinylphosphonic acid were very similar to those of untreated cotton; incorporating graphene into the cotton surface drastically increased its NIR absorption. Similar to the results obtained from our UV reflection evaluation, we found that the number of coating cycles and the graphene content were directly proportional to the NIR absorption abilities of cotton. An increased number of coating cycles and a larger amount of deposited graphene both boosted the efficiency of NIR absorption. It is worth noting the biomedical applications of graphene, which have been discussed elsewhere. ${ }^{57-59}$ Yang et al. introduced for the first time nanographene sheets for in vivo fluorescence imaging of tumor mouse models. These authors established the strong optical absorbance of graphene in the NIR region for in vivo photothermal therapy of cancer cells..$^{57}$ Qi et al. previously found that GO can be used in photodetector devices due to its excellent sensitivity to visible and NIR radiation..$^{58}$ Cao et al. recently conducted a comparative lab-scale investigation of the fabrication of RGO via LBL assembly. These authors evaluated the NIR absorption properties of graphene layers with different thicknesses and found that the NIR transmittances of thin films decreased with an increasing number of layers for radiation between 400 and $850 \mathrm{~nm} \cdot{ }^{59}$ All in all, we confirm here that graphene is a strong UV and NIR absorbing agent that can be used for coating applications on textile substrates; the absorption properties of the resulting materials can be iteratively tuned based on the number of layers and the graphene content. 


\subsection{Electrical conductivity and EMI shielding effectiveness}

Considering the fact that graphene exhibits electroconductive pathways in different polymeric nanocomposites, ${ }^{\mathbf{1 , 2}}$ we assessed this property of graphene/polyvinylphosphonic acid/cotton nanocomposites; we listed our results in Table 2 . In general, cellulose is known to be a non-conductive polymer with a high surface resistivity that acts as an insulating material. ${ }^{60}$ On the other hand, GO has a disrupted $\mathrm{sp}^{2}$ structure and is also categorized as an insulating material. ${ }^{\mathbf{1 , 2}}$ Several reducing agents such as $\mathrm{NaBH}_{4}, \mathrm{~N}_{2} \mathrm{H}_{4}, \mathrm{C}_{6} \mathrm{H}_{8} \mathrm{O}_{6}, \mathrm{~N}_{2} \mathrm{~S}_{2} \mathrm{O}_{4}$ and $\mathrm{NaOH}$ can convert GO to graphene and produce a low electrical resistance. ${ }^{7,8}$ As a result, high conductivity is achievable. Here, we used graphene in multiple coating on cotton; the graphene acted as an electroconductive agent without the need for reduction. On the other hand, we used polyvinylphosphonic acid for coating cotton to create an electronegative polymer to anchor graphene. We note that polyvinylphosphonic acid does not possess electrical conductivity properties; it is known to be an insulating polymer. ${ }^{47}$ Therefore, we expected to find graphene/ polyvinylphosphonic acid/cotton nanocomposites with moderate electrical conductivity. According to our results, the surface resistance of graphene/polyvinylphosphonic acid/ cotton nanocomposite prepared with 2 coating cycles was $181.67 \Omega$ per square; the surface resistance decreased to 152.92 $\Omega$ per square for the sample prepared with 5 coating cycles. We observed additional decreases in surface resistivity when we increased the number of coating cycles to 10. It is important to note that an increase in the graphene content in dispersion from 10 to $20 \mathrm{mg} \mathrm{ml}^{-1}$ enhanced the electrical conductivity. Several researchers have recently evaluated the electrical resistance of cotton after being coating of graphene, and these scientists reported similar enhancements., ${ }^{7,8,15,17,19}$ ShateriKhalilabad and Yazdanshenas found that the electrical conductivity of cotton increased as the number of coating cycles was increased from 1 to $20 .^{7,8}$ Molina et al. improved the electrical conductivity of cotton by employing the GO in the coating liquid. ${ }^{11}$ These authors also suggested the necessity of adding more coating layers to polyester due to the limited adhesion between graphene and the substrate. ${ }^{12,13}$ Javed et al. showed that the surface resistivities of GO-coated cotton and wool were diminished after UV curing. ${ }^{18}$ On the other hand, Karimi et al. proposed $\mathrm{TiCl}_{3}$ as titanium dioxide precursor to reduce GO on cotton. Their samples interestingly exhibited smaller electrical resistances than bare cotton., ${ }^{9,10}$ To study the electroconductivity of graphene/polyvinylphosphonic acid/cotton nanocomposites after washing, we used a standard method. Our results revealed that the washing process reduced the electrical conductivity of all of the nanocomposites independent of the number of coating layers. $\mathrm{Hu}$ et al. recently used a 10 -fold laundering process to evaluate the durability of graphene on cotton; these authors obtained results similar to ours. ${ }^{17}$ Here, we strongly suggest surface pretreatment methods such as plasma ionization and ultrasonic vibration to improve the durability properties and adhesion of the coating layers on the cotton. Our group previously confirmed such an improvement for the adhesion of lubrication agents on cotton and polyester substrates. ${ }^{22-26}$

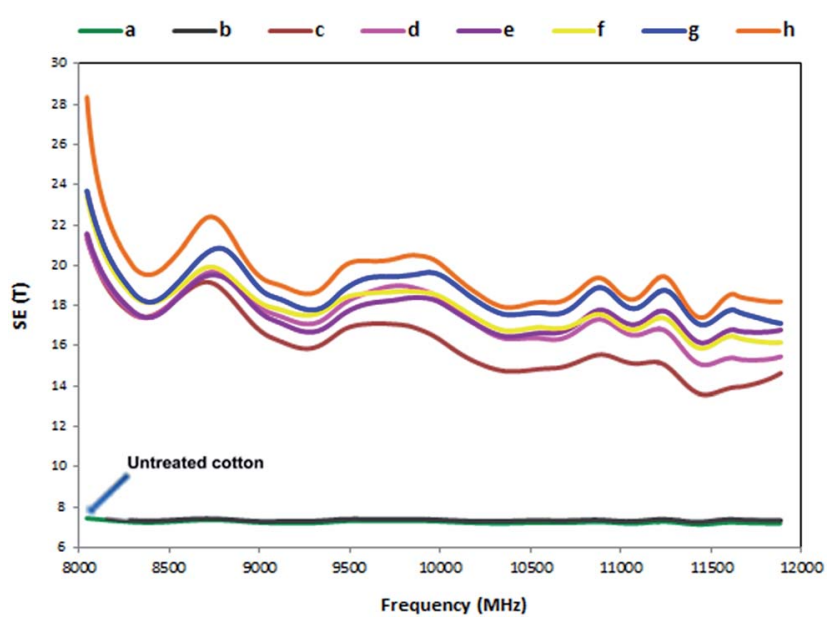

Fig. 10 The SET of different samples: (a) untreated cotton, (b) cotton coated with polyvinylphosphonic acid, (c) graphene/polyvinylphosphonic acid/cotton nanocomposite prepared with 2 coating cycles of $10 \mathrm{mg} \mathrm{ml}^{-1}$ FGN/CTAB colloidal dispersion and polyvinyl phosphonic acid, (d) graphene/polyvinylphosphonic acid/cotton nanocomposite prepared with 5 coating cycles of $10 \mathrm{mg} \mathrm{ml}^{-1} \mathrm{FGN} /$ CTAB colloidal dispersion and polyvinylphosphonic acid, (e) graphene/ polyvinylphosphonic acid/cotton nanocomposite prepared with 10 coating cycles of $10 \mathrm{mg} \mathrm{ml}^{-1}$ FGN/CTAB colloidal dispersion and polyvinylphosphonic acid, (f) graphene/polyvinylphosphonic acid/ cotton nanocomposite prepared with 2 coating cycles of $20 \mathrm{mg} \mathrm{ml}^{-1}$ FGN/CTAB colloidal dispersion and polyvinylphosphonic acid, (g) graphene/polyvinylphosphonic acid/cotton nanocomposite prepared with 5 coating cycles of $20 \mathrm{mg} \mathrm{ml}^{-1}$ FGN/CTAB colloidal dispersion and polyvinylphosphonic acid, (h) graphene/polyvinylphosphonic acid/cotton nanocomposite prepared with 10 coating cycles of $20 \mathrm{mg}$ $\mathrm{ml}^{-1} \mathrm{FGN} / \mathrm{CTAB}$ colloidal dispersion and polyvinylphosphonic acid.

Table 2 The surface resistance and electrical conductivity of different samples produced in this study before and after washing

\begin{tabular}{|c|c|c|c|c|c|}
\hline \multirow{2}{*}{$\begin{array}{l}\text { Number of } \\
\text { coating cycles }\end{array}$} & \multirow{2}{*}{$\begin{array}{l}\text { Graphene content in } \\
\text { dispersion }\left(\mathrm{mg} \mathrm{ml}^{-1}\right)\end{array}$} & \multicolumn{2}{|c|}{ Surface resistance ( $\Omega$ per square) } & \multicolumn{2}{|c|}{ Electrical conductivity $\left(\mathrm{S} \mathrm{cm}^{-1}\right)$} \\
\hline & & Before washing & After washing & Before washing & After washing \\
\hline 2 & 10 & 181.67 & 220 & 0.0055 & 0.0045 \\
\hline 5 & 10 & 152.92 & 155.83 & 0.0065 & 0.0064 \\
\hline 10 & 10 & 131.25 & 137.92 & 0.0076 & 0.0073 \\
\hline 2 & 20 & 75 & 80 & 0.0133 & 0.0125 \\
\hline 5 & 20 & 43.75 & 48.33 & 0.0229 & 0.0207 \\
\hline 10 & 20 & 40.83 & 50.42 & 0.0245 & 0.0198 \\
\hline
\end{tabular}


It stands to reason that the effectiveness of EMI shielding has a direct relationship with the conductivity of shielding materials. ${ }^{61}$ The total EMI shielding effectiveness (SET) is the sum of the absorption character (SEA) and reflection character (SER) (eqn (4)). In these materials, multiple reflections (SEM) are not significant and can be neglected:

$$
\mathrm{SET} \approx \mathrm{SEA}+\mathrm{SER}
$$

Fig. 10 shows a graph of SET of the nanocomposites over the frequency range 8000-12 $000 \mathrm{MHz}$. We note that the largest SE values were obtained at the measured frequencies for the graphene/polyvinylphosphonic acid/cotton nanocomposite prepared with 10 coating cycles and the $20 \mathrm{mg} \mathrm{ml}^{-1}$ graphene content. Consistent with our previous results of electrical conductivity, SE increased when we immobilized graphene onto the cotton surface. This observation suggests that graphene can significantly absorb electromagnetic waves of different substrates via coating. We have recently introduced several electromagnetic shielding materials for use in composites. ${ }^{\mathbf{6 2 - 6 5}}$ In this regard, we have found that nanoparticles such as carbon nanotubes, ${ }^{37}$ silica, ${ }^{65} \mathrm{ZrO}_{2},{ }^{66}$ nanocomposite particles of polypyrrole/silver ${ }^{53}$ and silver/silica/kaolinite are ideal candidates for electromagnetic shielding purposes. ${ }^{64}$

\section{Conclusion}

In summary, we have demonstrated a novel approach for anchoring graphene on cotton via LBL coating using polyvinylphosphonic acid as an anionic polymer. FGNs exhibited a negative zeta potential value with precipitation in aqueous solution; the CTAB/FGN colloidal dispersions were highly stable in water and exhibited positive zeta values. We have proposed two different CTAB assembly mechanisms on FGN sheets: lamellar and spherical. Several changes were observed in the FTIR spectra of graphene/polyvinylphosphonic acid/cotton nanocomposites, which confirm the successful deposition of nanosheets and polymer on the cellulose. We also found that the hydrophobicity of the cotton increased after the addition of the graphene and polyvinylphosphonic acid coatings due to the increase in the water contact angle values of the samples. According to our results, the degree of hydrophobicity depended on the number of coating cycles and the FGN content in the colloidal dispersion. Furthermore, the thermal stability, electrical conductivity, UV absorption and EMI shielding of the graphene/polyvinylphosphonic acid/cotton nanocomposites were improved compared with untreated cotton. All in all, we conclude that our new inorganic/organic nanocomposite coating method is a very promising tool for achieving multifunctional properties of cellulosic substrates.

\section{References}

1 S. Thakur and N. Karak, Alternative methods and naturebased reagents for the reduction of graphene oxide: A review, Carbon, 2015, 94, 224-242.
2 A. Zurutuza and C. Marinelli, Challenges and opportunities in graphene commercialization, Nat. Nanotechnol., 2014, 9, 730-734.

3 M. J. Nine, M. A. Cole, D. N. H. Tran and D. Losic, Graphene: a multipurpose material for protective coatings, J. Mater. Chem. A, 2015, 3, 12580-12602.

4 J.-Z. Chen, C.-C. Hsu, C. Wang, W.-Y. Liao, C.-H. Wu, T.-J. Wu, H.-W. Liu, H. Chang, S.-T. Lien, H.-C. Li, C.-M. Hsu, P.-K. Kao, Y.-J. Yang and I.-C. Cheng, Rapid Atmospheric-Pressure-Plasma-Jet Processed Porous Materials for Energy Harvesting and Storage Devices, Coatings, 2015, 5, 26-38.

5 B. Fugetsu, E. Sano, H. Yu, K. Mori and T. Tanaka, Graphene oxide as dyestuffs for the creation of electrically conductive fabrics, Carbon, 2010, 48, 3340-3345.

6 X. Liu, Z. Qin, Z. Dou, N. Liu, L. Chen and M. Zhu, Fabricating conductive poly(ethylene terephthalate) nonwoven fabrics using an aqueous dispersion of reduced graphene oxide as a sheet dyestuff, RSC Adv., 2014, 4, 23869-23875.

7 M. Shateri-Khalilabad and M. E. Yazdanshenas, Fabricating electroconductive cotton textiles using graphene, Carbohydr. Polym., 2013, 96, 190-195.

8 M. Shateri-Khalilabad and M. E. Yazdanshenas, Preparation of superhydrophobic electroconductive graphene-coated cotton cellulose, Cellulose, 2013, 20, 963-972.

9 L. Karimi, M. E. Yazdanshenas, R. Khajavi, A. Rashidi and M. Mirjalili, Using graphene/ $/ \mathrm{TiO}_{2}$ nanocomposite as a new route for preparation of electroconductive, self-cleaning, antibacterial and antifungal cotton fabric without toxicity, Cellulose, 2014, 21, 3813-3827.

10 L. Karimi, M. E. Yazdanshenas, R. Khajavi, A. Rashidi and M. Mirjalili, Functional finishing of cotton fabrics using graphene oxide nanosheets decorated with titanium dioxide nanoparticles, J. Text. Inst., 2015, DOI: 10.1080/ 00405000.2015.1093311.

11 J. Molina, J. Fernández, A. I. del Río, J. Bonastre and F. Cases, Chemical and electrochemical study of fabrics coated with reduced graphene oxide, Appl. Surf. Sci., 2013, 279, 46-54.

12 J. Molina, A. Zille, J. Fernández, A. P. Souto, J. Bonastre and F. Cases, Conducting fabrics of polyester coated with polypyrrole and doped with graphene oxide, Synth. Met., 2015, 204, 110-121.

13 J. Molina, F. Fernandes, J. Fernández, M. Pastor, A. Correia, A. P. Souto, J. O. Carneiro, V. Teixeira and F. Cases, Photocatalytic fabrics based on reduced graphene oxide and $\mathrm{TiO}_{2}$ coatings, Mater. Sci. Eng., B, 2015, 199, 62-76.

14 S. Ramasundaram, J. H. Jung, E. Chung, S. K. Maeng, S. H. Lee, K. G. Song and S. W. Hong, Increasing hydrophobicity of poly(propylene) fibers by coating reduced graphene oxide and their application as depth filter media, Carbon, 2014, 70, 179-189.

15 L. Qu, M. Tian, X. Hu, Y. Wang, S. Zhu, X. Guo, G. Han, X. Zhang, K. Sun and X. Tang, Functionalization of cotton fabric at low graphene nanoplate content for ultrastrong ultraviolet blocking, Carbon, 2014, 80, 565-574. 
16 Y. Tang, Z. He, J. A. Mosseler and Y. Ni, Production of highly electro-conductive cellulosic paper via surface coating of carbon nanotube/graphene oxide nanocomposites using nanocrystalline cellulose as a binder, Cellulose, 2014, 21, 4569-4581.

17 X. Hu, M. Tian, L. Qu, S. Zhu and G. Han, Multifunctional cotton fabrics with graphene/polyurethane coatings with far-infrared emission, electrical conductivity, and ultraviolet blocking properties, Carbon, 2015, 95, 625-633.

18 K. Javed, C. M. A. Galib, F. Yang, C.-M. Chen and C. Wang, A new approach to fabricate graphene electro-conductive networkson natural fibers by ultraviolet curing method, Synth. Met., 2014, 193, 41-47.

19 L.-L. Xu, M.-X. Guo, S. Liu and S.-W. Bian, Graphene/cotton composite fabrics as flexible electrode materials for electrochemical capacitors, RSC Adv., 2015, 5, 25244-25249.

20 I. A. Sahito, K. C. Sun, A. A. Arbab, M. B. Qadir and S. H. Jeong, Graphene coated cotton fabric as textile structured counter electrode for DSSC, Electrochim. Acta, 2015, 173, 164-171.

21 D. H. Ha, S. Jung, H.-J. Kim, D. Kim, W.-J. Kim, S. N. Yi, Y. Jun and Y. J. Yun, Transition of graphene oxide-coated fiber bundles from insulator to conductor by chemical reduction, Synth. Met., 2015, 204, 90-94.

22 M. Parvinzadeh and I. Ebrahimi, Atmospheric air-plasma treatment of polyester fiber to improve the performance of nanoemulsion silicone, Appl. Surf. Sci., 2010, 257, 40624068.

23 M. Parvinzadeh and I. Ebrahimi, Influence of atmosphericair plasma on the coating of a nonionic lubricating agent on polyester fiber, Radiat. Eff. Defects Solids, 2011, 166, 408-416.

24 I. Ebrahimi, A. Kiumarsi, M. Parvinzadeh Gashti, R. Rashidian and M. H. Norouzi, Atmospheric-air plasma enhances coating of different lubricating agents on polyester fiber, Eur. Phys. J.: Appl. Phys., 2011, 56, 10801.

25 M. Parvinzadeh Gashti, D. Hegemann, M. Stir and J. Hulliger, Thin Film Plasma Functionalization of Polyethylene Terephthalate to Induce Bone-Like Hydroxyapatite Nanocrystals, Plasma Processes Polym., 2014, 11, 37-43.

26 M. Parvinzadeh Gashti, I. Ebrahimi and M. Pousti, New insights into corona discharge surface ionization of polyethylene terephthalate via a combined computational and experimental assessment, Curr. Appl. Phys., 2015, 15, 1075-1083.

27 J. Molina, J. Fernández, M. Fernandes, A. P. Souto, M. F. Esteves, J. Bonastre and F. Cases, Plasma treatment of polyester fabrics to increase the adhesion of reduced graphene oxide, Synth. Met., 2015, 202, 110-122.

28 G. Huang, J. Yang, J. Gao and X. Wang, Thin films of intumescent flame retardant-polyacrylamide and exfoliated graphene oxide fabricated via layer-by-layer assembly for improving flame retardant properties of cotton fabric, Ind. Eng. Chem. Res., 2012, 51, 12355-12366.

29 M. Tian, X. Hu, L. Qu, S. Zhu, Y. Sun and G. Han, Versatile and ductile cotton fabric achieved via layer-by-layer self- assembly by consecutive adsorption of graphene doped PEDOT: PSS and chitosan, Carbon, 2016, 96, 1166-1174.

30 M. P. Gashti, F. Alimohammadi and A. Shamei, Preparation of water-repellent cellulose fibers using a polycarboxylic acid/hydrophobic silica nanocomposite coating, Surf. Coat. Technol., 2012, 206, 3208-3215.

31 F. Alimohammadi, M. P. Gashti and A. Shamei, A novel method for coating of carbon nanotube on cellulose fiber using 1, 2, 3, 4-butanetetracarboxylic acid as a crosslinking agent, Prog. Org. Coat., 2012, 74, 470-478.

$32 \mathrm{M}$. P. Gashti and A. Almasian, Citric acid/ $/ \mathrm{ZrO}_{2}$ nanocomposite inducing thermal barrier and self-cleaning properties on protein fibers, Composites, Part B, 2013, 52, 340-349.

33 K. Kakaei and K. Hasanpour, Synthesis of graphene oxide nanosheets by electrochemical exfoliation of graphite in cetyltrimethylammonium bromide and its application for oxygen reduction, J. Mater. Chem. A, 2014, 2, 15428-15436.

34 L. Guardia, M. J. Fernández-Merino, J. I. Paredes, P. SolísFernández, S. Villar-Rodil, A. Martínez-Alonso and J. M. D. Tascón, High-throughput production of pristine graphene in an aqueous dispersion assisted by non-ionic surfactants, Carbon, 2011, 49, 1653-1662.

35 S. Vadukumpully, J. Paul and S. Valiyaveettil, Cationic surfactant mediated exfoliation of graphite into graphene flakes, Carbon, 2009, 47, 3288-3294.

36 K. Das, S. Maiti, M. Ghosh, D. Mandal and P. K. Das, Graphene oxide in cetyltrimethylammonium bromide (CTAB) reverse micelle: A befitting soft nanocomposite for improving efficiency of surface-active enzymes, J. Colloid Interface Sci., 2013, 395, 111-118.

37 F. Alimohammadi, M. P. Gashti and A. Shamei, Functional cellulose fibers via polycarboxylic acid/carbon nanotube composite coating, J. Coat. Technol. Res., 2013, 10, 123-132.

38 J. Lim, N.-E. Lee, E. Lee and S. Yoon, Surface Modification of Citrate-Capped Gold Nanoparticles Using CTAB Micelles, Bull. Korean Chem. Soc., 2014, 35, 2567-2569.

39 E. E. Tkalya, M. Ghislandi, G. de With and C. E. Koning, The use of surfactants for dispersing carbon nanotubes and graphene to make conductive nanocomposites, Curr. Opin. Colloid Interface Sci., 2012, 17, 225-232.

40 J. Zhao, B. Deng, M. Lv, J. Li, Y. Zhang, H. Jiang, C. Peng, J. Li, J. Shi, Q. Huang and C. Fan, Graphene oxide-based antibacterial cotton fabrics, Adv. Healthcare Mater., 2013, 2, 1259-1266.

41 M. P. Gashti, A. Pournaserani, H. Ehsani and M. P. Gashti, Surface oxidation of cellulose by ozone-gas in a vacuum cylinder to improve the functionality of fluoromonomer, Vacuum, 2013, 91, 7-13.

42 M. B. Lim, M. Hu, S. Manandhar, A. Sakshaug, A. Strong, L. Riley and P. J. Pauzauskie, Ultrafast sol-gel synthesis of graphene aerogel materials, Carbon, 2015, 95, 616-624.

43 M. P. Gashti and A. Almasian, UV radiation induced flame retardant cellulose fiber by using polyvinylphosphonic acid/carbon nanotube composite coating, Composites, Part $B, 2013,45,282-289$. 
44 P. K. Chidambareswaran, S. Sreenivasan, N. B. Patil, M. S. Parthasarathy and B. Srinathan, Analysis of some textile blends using their X-ray diffraction patterns, Text. Res. J., 1987, 57, 167-171.

45 K. Jiao, T. Zhu, X. Li, M. Shan, Z. Xu and Y. Jiao, Assembly of graphene oxide on nonconductive nonwovens by the synergistic effect of interception and electrophoresis, $J$. Nanopart. Res., 2015, 17, DOI: 10.1007/s11051-015-3177-0.

46 M. P. Gashti, F. Alimohammadi, G. Song and A. Kiumarsi, Characterization of nanocomposite coatings on textiles: a brief review on microscopic technology, Current Microscopy Contributions to Advances in Science and Technology, 2012, 2, 1424-1437.

47 L. Macarie and G. Ilia, Poly(vinylphosphonic acid) and its derivatives, Prog. Polym. Sci., 2010, 35, 1078-1092.

48 M. H. Rahimi, M. Parvinzadeh, M. Y. Navid and S. Ahmadi, Thermal characterization and flammability of polyester fiber coated with nonionic and cationic softeners, J. Surfactants Deterg., 2011, 14, 595-603.

49 M. P. Gashti, M. Y. Navid and M. H. Rahimi, Coating of macroemulsion and microemulsion silicones on poly (ethylene terephthalate) fibers: Evaluation of the thermal properties and flammability, J. Appl. Polym. Sci., 2012, 125, 1430-1438.

50 M. Parvinzadeh Gashti, M. Yousefpour Navid and M. Hossein Rahimi, Effects of coating of nano-and microemulsion silicones on thermal properties and flammability of polyethylene terephthalate textile, Pigm. Resin Technol., 2013, 42, 34-44.

51 N. Abidi, L. Cabrales and E. Hequet, Thermogravimetric analysis of developing cotton fibers, Thermochim. Acta, 2010, 498, 27-32.

52 M. P. Gashti, A. Elahi and M. P. Gashti, UV radiation inducing succinic acid/silica-kaolinite network on cellulose fiber to improve the functionality, Composites, Part B, 2013, 48, 158-166.

53 M. P. Gashti, S. T. Ghehi, S. V. Arekhloo, A. Mirsmaeeli and A. Kiumarsi, Electromagnetic shielding response of UVinduced polypyrrole/silver coated wool, Fibers Polym., 2015, 16, 585-592.

54 D. Saravanan, UV protection textile materials, Autex Res. J., 2007, 7, 53-62.

55 S. Gowri, L. Almeida, T. Amorim, N. Carneiro, A. P. Souto and M. F. Esteves, Polymer nanocomposites for multifunctional finishing of textiles - a review, Text. Res. J., 2010, 80, 1290-1306.

56 I. Ebrahimi and M. Parvinzadeh Gashti, Extraction of juglone from Pterocarya fraxinifolia leaves for dyeing, antifungal finishing, and solar UV protection of wool, Color. Technol., 2015, 131, 451-457.

57 K. Yang, S. Zhang, G. Zhang, X. Sun, S.-T. Lee and Z. Liu, Graphene in mice: Ultrahigh in vivo tumor uptake and efficient photothermal therapy, Nano Lett., 2010, 10, 33183323.

58 X. Qi, X. Zou, Z. Huang, L. Ren, G. Hao, Y. Liu, X. Wei and J. Zhong, Ultraviolet, visible, and near infrared photoresponse properties of solution processed graphene oxide, Appl. Surf. Sci., 2013, 266, 332-336.

59 Y. Cao, J. Zhu, J. Xu and J. He, Tunable near-infrared photovoltaic and photoconductive properties of reduced graphene oxide thin films by controlling the number of reduced graphene oxide bilayers, Carbon, 2014, 77, 11111122.

60 R. J. Moon, A. Martini, J. Nairn, J. Simonsen and J. Youngblood, Cellulose nanomaterials review: structure, properties and nanocomposites, Chem. Soc. Rev., 2011, 40, 3941-3994.

61 D. D. L. Chung, Electromagnetic interference shielding effectiveness of carbon materials, Carbon, 2001, 39, 279-285.

62 M. Parvinzadeh and S. Eslami, Optical and electromagnetic characteristics of clay-iron oxide nanocomposites, Res. Chem. Intermed., 2011, 37, 771-784.

63 M. P. Gashti and S. Eslami, Structural, optical and electromagnetic properties of aluminum-clay nanocomposites, Superlattices Microstruct., 2012, 51, 135-148.

64 M. P. Gashti and A. Almasian, Synthesizing tertiary silver/silica/ kaolinite nanocomposite using photo-reduction method: Characterization of morphology and electromagnetic properties, Composites, Part B, 2012, 43, 3374-3383.

65 M. P. Gashti, R. Hajiraissi and M. P. Gashti, Morphological, optical and electromagnetic characterization of polybutylene terephthalate/silica nanocomposites, Fibers Polym., 2013, 14, 1324-1331.

66 M. P. Gashti, A. Almasian and M. P. Gashti, Preparation of electromagnetic reflective wool using nano- $\mathrm{ZrO}_{2} /$ citric acid as inorganic/organic hybrid coating, Sens. Actuators, A, 2012, 187, 1-9. 